\title{
Electrode Migration: A Review Article
}

\author{
Abdulmalik A Alkhodair*, Abdulrahman F Aljadoa, Mohammed S Alobayli, Sahar M Bin Dehaish and Fahad N \\ Altamimi
}

Department of Otolaryngology Head and Neck Surgery, King Saud Medical City, Saudi Arabia

Submission: June 28, 2020; Published: July 14, 2020

*Corresponding author: Abdulmalik A Alkhodair, Department of Otolaryngology Head and Neck Surgery, King Saud Medical City, Riyadh, Saudi

\begin{abstract}
Cochlear implant (CI) is considered as safe, and effective surgical procedure for patients with Sensory Neural Hearing Loss (SNHL). The cochlear implant is an electronic device implanted behind the ear, with electrode arrays which are inserted into the Scala Tympani of the cochlea to stimulate the auditory pathway. The complications rate of cochlear implant surgery is very low, and more common in pediatrics. Furthermore, electrode migration is one of the complications which are defined as gradual slipping out of electrode from cochlea or extrusion from tympanic membrane. Data were being collected through search engines included PUBMED, Google Scholar, and BMJ. The process of sorting out of articles as per inclusion criteria which has an outcome related to electrode migration in post cochlear implant. After removal of duplicate studies, total of 12 articles were found eligible for review analysis. Electrode migration is more common as previously reported, it has shown that fixation techniques should be more reliable to avoid migration of electrode. The purpose of this study is to get a detailed review of electrode migration causes and prevalence in post cochlear implant patients and what factors can lead to migration intraoperative and post-operative cases.
\end{abstract}

Keywords: Electrode migration; Sensory neural hearing Loss; Cochlear implant

\section{Introduction}

Cochlear implant (CI) is a well-known, safe, and effective surgical procedure for patients with Sensory Neural Hearing Loss (SNHL), which is a type of hearing loss due to either inner ear pathologies, or Vestibulocochlear nerve (VIII) damage [1]. Moreover, it is reported that $20 \%$ of patients with congenital SNHL have a concurrent inner ear malformation [2]. Despite of multiple treatment options have been applied; however, cochlear implant (CI) surgery is the mainstay of surgical treatment. In addition, Cochlear implant is an electronic device implanted behind the ear, with electrode arrays which are inserted into the scala tympani of the cochlea to stimulate the auditory pathway [3,4]. Moreover, cochlear implant device has two types of electrodes: Straight lateral wall (LW) electrode arrays, and Perimodiolar electrode arrays [5].

As any other surgical procedures, the complication rate of cochlear implant surgery is very low, and reported around 3-10\% of all CI surgeries, common in pediatric patients [6]. Furthermore, electrode migration or extrusion is an important complication in CI surgery, which affects the hearing level, and induce facial nerve stimulation, that may require a revision. Electrode migration is defined as a complication due to gradually slip out of electrodes from cochlea or extrusion from the tympanic membrane [7] due to raise the level of impedance values in basal side electrodes. As well as, it can be due to cochlear ossification (Figure 1) [8]. Moreover, it has been reported that $1-15 \%$ of patients who underwent revision CI surgery have had an electrode migration $[9,10]$. The purpose of this study is to get a detailed review of electrode migration causes and prevalence in post cochlear implant patients and what factors can lead to migration intraoperative and post-operative cases.

\section{Material and Methodology}

The study design was cross sectional review study. Data were being collected through search engines included PUBMED, Google Scholar, and BMJ. Quality assessment of an article done as per defined criteria. Previously published article searched based on electrode migration post Cochlear implant (CI). An electronic search as per medical subject headings (Mesh) was carried out and by using different search engines like Google scholar, PUB MED, WEBMED to increase sensitivity of electrode migration after CI. A Literature search done and in a systematic way of previously published articles and limited to English language.

Each article was critically analyzed and appraised as per study inclusion criteria and fulfilling the following criteria. 


\section{Global Journal of Otolaryngology}
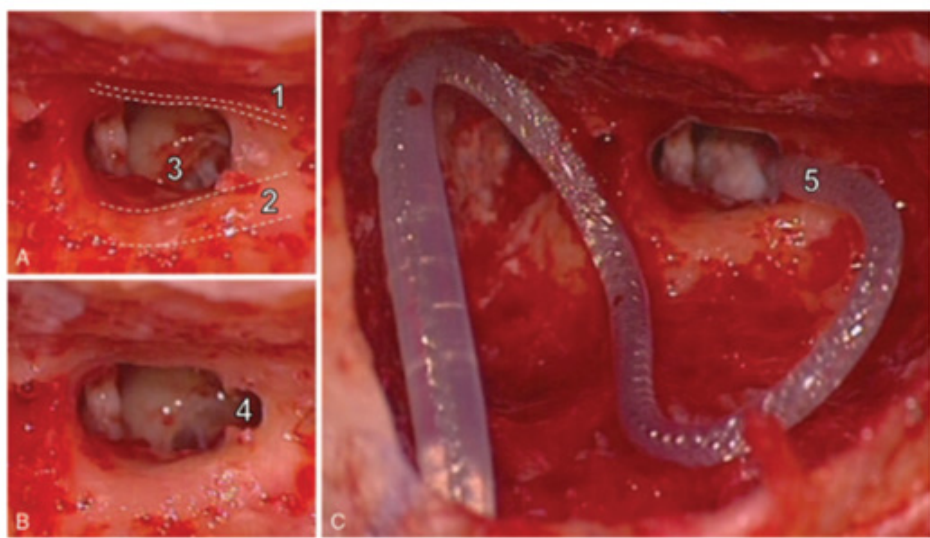

Figure 1: Bone groove created in facial recess to fixate the electrode.1) Chorda tympani, 2) facial nerve, 3) round window membrane, In panel $B$ of figure showed the recommended position of bone while panel c showed electrode fixation through sigmoidal course of sigmoid lead [8].

a) Article published between in 2008-2019.

b) Article in which complications of CI are found.

c) Article which emphasize on electrode migration post CI.

d) Article gives prevalence and incidence of complications in post CI and clearly

e) Found with respect of duration of the implant.

f) Article published in English language.

Articles published during 2008 to 2019 duration were added as their electrode migration considered as a rare and underrated complication after $\mathrm{CI}$, therefor better approach and to understand the possible factors affecting on electrode migration. While conference papers, articles in abstract form and duplicated were excluded from the search. The authors extracted data in the form of sample size, study settings, publication year, study point and overall theme of article from articles which was included in study.
Authors also confirmed the quality of articles in term of the title and contents.

\section{Result}

Of the first 98 peer review articles found on electrode migration in post cochlear implant in which include bone grove electrode migration and perimodiolar electrode migration were segregated as per search method in (Figure 2). Furthermore, Figure 2 summarizes the process of choice of articles as per inclusion criteria and which has an outcome and comparison related to electrode migration in post cochlear implant. After removal of duplicated studies and those studies which are inappropriate and irrelevant to do with electrode emigration in post cochlear implant. A total of 12 articles were found eligible for review analysis. These articles included of 583 total patients. The patient age range is from 2.5 years to 79 years, with duration of follow up period in selected studies were 6 months to five years.

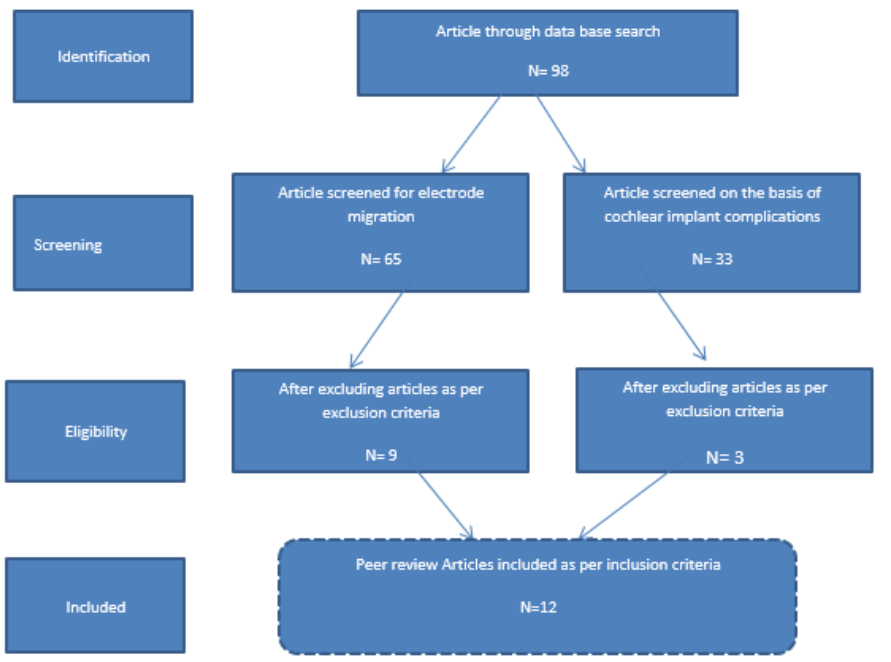

Figure 2: Literature review process on electrode migration post cochlear implant. 


\section{Global Journal of Otolaryngology}

A total of 10 peer reviewed publication reported on electrode migration in post cochlear implant was found from the database. All these articles applied to electrode migration either it is bone grooving or perimodiolar electrode migration. Characteristics of each study given in Table 1 which summarizes the electrode migration with different and advance strategy for cochlear implant. Studies by J holder et al. and sunde et al. [12] in which 262 patients were observed after implantation, out of which 9 $(25.7 \%)$ patients had incomplete insertion of electrodes, and in $2(6.0 \%)$ patients reported with electrode migration which was observed through CT scan and $0.9 \%$ device failure due to electrode migration respectively [11,12].

Table 1: characteristics of selected studies.

\begin{tabular}{|c|c|c|c|c|c|c|c|}
\hline Study \& Year & Method & Sample Size & $\begin{array}{l}\text { Reason for Reim- } \\
\text { plantation }\end{array}$ & $\begin{array}{l}\text { Electrode Migration } \\
\text { Measurement }\end{array}$ & $\begin{array}{l}\text { Type of Elec- } \\
\text { trodes }\end{array}$ & $P$ Value & $\begin{array}{l}\text { Frequency of } \\
\text { Clinical Symp- } \\
\text { toms }\end{array}$ \\
\hline $\begin{array}{l}\text { Vander marel K S, } \\
\text { et al. [14] }\end{array}$ & Metanalysis & $\mathrm{N}=35$ & $\begin{array}{l}\text { Device failure and } \\
\text { drop in performance }\end{array}$ & $\begin{array}{l}>1 \mathrm{~mm} \text { in HiFocusIJ } \\
<1 \mathrm{~mm} \text { in HiFocusI }\end{array}$ & HiFocus1J & 0 & $5 \%$ \\
\hline Dietz et al. [15] & Case Control & $\mathrm{N}=12$ & $\begin{array}{l}\text { Drop in perfor- } \\
\text { mance }\end{array}$ & $>1 \mathrm{~mm}$ & $\begin{array}{l}\text { Lateral wall } \\
\text { electrodes }\end{array}$ & 0.03 & $2 \%$ \\
\hline Connell et al. [10] & $\begin{array}{l}\text { Systematic } \\
\text { review }\end{array}$ & $\mathrm{N}=08$ & $\begin{array}{l}\text { Drop in perfor- } \\
\text { mance }\end{array}$ & $>1 \mathrm{~mm}$ & $\begin{array}{l}\text { Modiolur elec- } \\
\text { trodes }\end{array}$ & 0.05 & $3.80 \%$ \\
\hline Leinung et al. [8] & $\begin{array}{c}\text { Cross } \\
\text { sectional } \\
\text { observational }\end{array}$ & $\mathrm{N}=29$ & $\begin{array}{l}\text { Drop in perfor- } \\
\text { mance }\end{array}$ & $\begin{array}{l}>1 \mathrm{~mm} \text { in Modiolur } \\
\text { electrodes }<1 \mathrm{~mm} \text { in } \\
\text { lateral electrodes }\end{array}$ & $\begin{array}{l}\text { Modiolur elec- } \\
\text { trodes }\end{array}$ & 0.03 & $4.20 \%$ \\
\hline Mittman et al. [7] & Case control & $\mathrm{N}=27$ & $\begin{array}{l}\text { Drop in perfor- } \\
\text { mance }\end{array}$ & $>1 \mathrm{~mm}$ & $\begin{array}{l}\text { Modiolur elec- } \\
\text { trodes }\end{array}$ & 0.05 & $3.20 \%$ \\
\hline Wamna et al. 2014 & Metanalysis & $N=116$ & Painful stimulation & $>1 \mathrm{~mm}$ & $\begin{array}{l}\text { Modiolur elec- } \\
\text { trodes }\end{array}$ & 0.03 & $2 \%$ \\
\hline $\begin{array}{c}\text { Waltzman et al. } \\
\text { [21] }\end{array}$ & $\begin{array}{l}\text { Observa- } \\
\text { tional }\end{array}$ & $N=133$ & $\begin{array}{l}\text { Drop in perfor- } \\
\text { mance }\end{array}$ & $>2 \mathrm{~mm}$ & $\begin{array}{l}\text { Modiolur elec- } \\
\text { trodes }\end{array}$ & 0.05 & $4 \%$ \\
\hline Fischer et al. [19] & $\begin{array}{l}\text { Retrospective } \\
\text { review }\end{array}$ & $N=63$ & $\begin{array}{l}\text { Drop in perfor- } \\
\text { mance }\end{array}$ & $\begin{array}{l}>1 \mathrm{~mm} \text { in HiFocusIJ } \\
<1 \mathrm{~mm} \text { in HiFocusI }\end{array}$ & HiFocus1J & 0.02 & $1.70 \%$ \\
\hline Grolmela et al. [13] & $\begin{array}{l}\text { Retrospective } \\
\text { review }\end{array}$ & $\mathrm{N}=72$ & $\begin{array}{l}\text { Drop in perfor- } \\
\text { mance }\end{array}$ & $>1 \mathrm{~mm}$ & $\begin{array}{l}\text { Lateral wall } \\
\text { electrodes }\end{array}$ & 0.04 & $3.40 \%$ \\
\hline Bennink et al. 2017 & Metanalysis & $\mathrm{N}=65$ & $\begin{array}{l}\text { Drop in perfor- } \\
\text { mance and painful } \\
\text { stimulation }\end{array}$ & $>1 \mathrm{~mm}$ & $\begin{array}{l}\text { Modiolur elec- } \\
\text { trodes }\end{array}$ & 0.05 & $3.00 \%$ \\
\hline Spari et al. [10] & $\begin{array}{l}\text { Cross sec- } \\
\text { tional }\end{array}$ & $N=23$ & $\begin{array}{l}\text { Drop in perfor- } \\
\text { mance }\end{array}$ & $\begin{array}{l}>1 \mathrm{~mm} \text { in Modiolur } \\
\text { electrodes }<1 \mathrm{~mm} \text { in } \\
\text { lateral electrodes }\end{array}$ & $\begin{array}{l}\text { Modiolur elec- } \\
\text { trodes }\end{array}$ & 0.01 & $5.20 \%$ \\
\hline Holder et al. [11] & Retrospective & $\mathrm{N}=35$ & $\begin{array}{l}\text { Prevalence of elec- } \\
\text { trode migration }\end{array}$ & $>1 \mathrm{~mm}$ & $\begin{array}{l}\text { Modular elec- } \\
\text { trode }\end{array}$ & 0 & $\begin{array}{l}\text { Not objected in } \\
\text { study. }\end{array}$ \\
\hline
\end{tabular}

Additionally, Kevin D Brown et al has followed up 806 patients with cochlear implant and it has been found that most common reason for reimplantation is device failure which is $78 \%$ out of which $55 \%$ is hard failure and $23 \%$ soft failure which is further followed by electrode migration that is reported around 9\% [13]. In another study published by Van der et al. [14] it was analyzed that electrode positioning evaluated in 35 patients with cochlear implant out of which 16 patients were with non-positioner C11 Hi Focus 1 and 19 were with HiRes 90K using multiplanar reconstruction [14]. This study was a retrospective study and out of 35 patients, 5 patients were evaluated with complaints like vertigo, tinnitus and headache and electrode migration may correlate with implant type, insertion depth or presence of complaints. It is found that Migrations were detected in 10 patients (29\%).
There was a significant effect of the implant type in favor of the HiFocus1, but there is no relation to the original insertion depth of the device. Out of 35 there are 5 patients scanned because of signs and symptoms of tinnitus and vertigo, 2 patients with migrations were detected. Comparison of different electrode types with clinical symptoms or without complaints is shown in (Figure 3). The issues of electrode migration of post $\mathrm{CI}$ are associated with lateral wall electrodes by Dietz et al. [15] and Vaid et al. [16] described the factors which are involved in electrode extrusion or migration, which are classified on the basis of intracochlear which pushes the electrode, like cochlear ossification $[15,16]$.

Furthermore, extracochlear causes like wire coiling, mastoid adhesion, electrode type, and electrode depth of insertion. To elaborate it, electrode with deeper insertion has least chances of migration after implant while partially inserted electrodes are 
more prone to migrate. Frequency of electrode migration, and causative factors after cochlear implant are shown in (Figure 4). In addition, case report by J Otol et al. 2019 discussed about the cholesteatoma effect on electrode migration if there are any signs, symptoms related to it or before going to cochlear implant, must consider it as it later on causes device failure due to electrode migration [17].

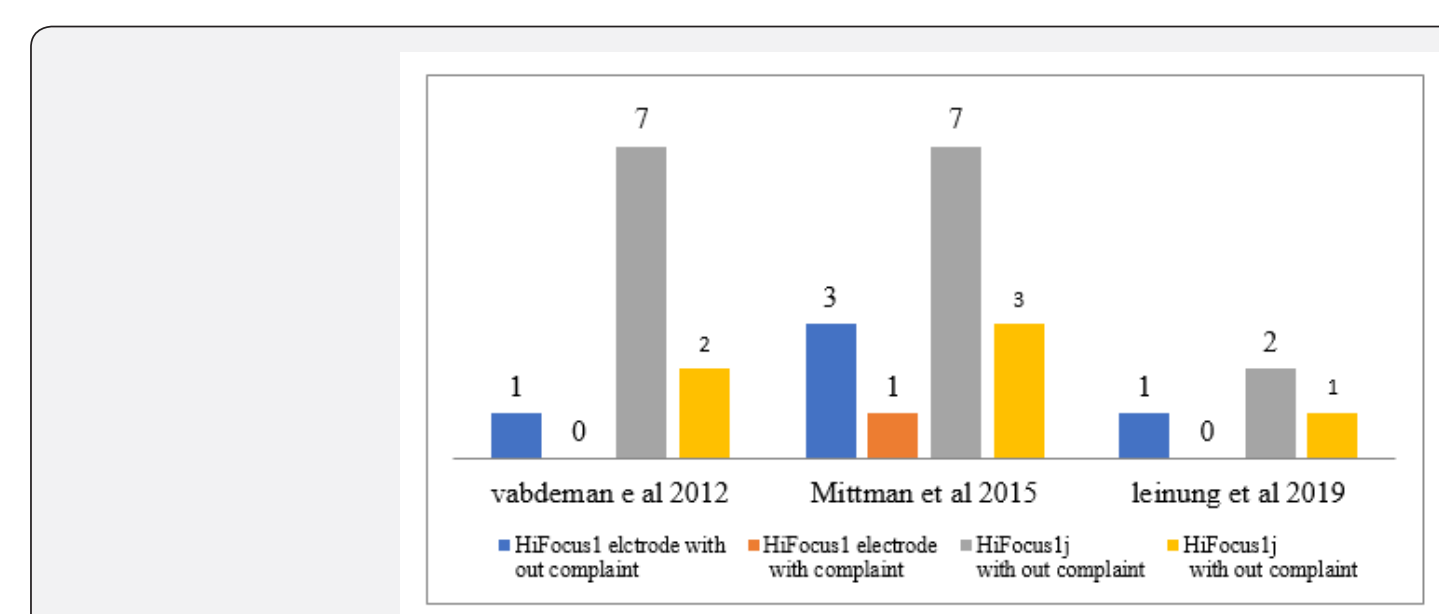

Figure 3: Comparison of electrode (HiFocus1 type electrode) migration in respect of different electrode with and without clinical symptoms.

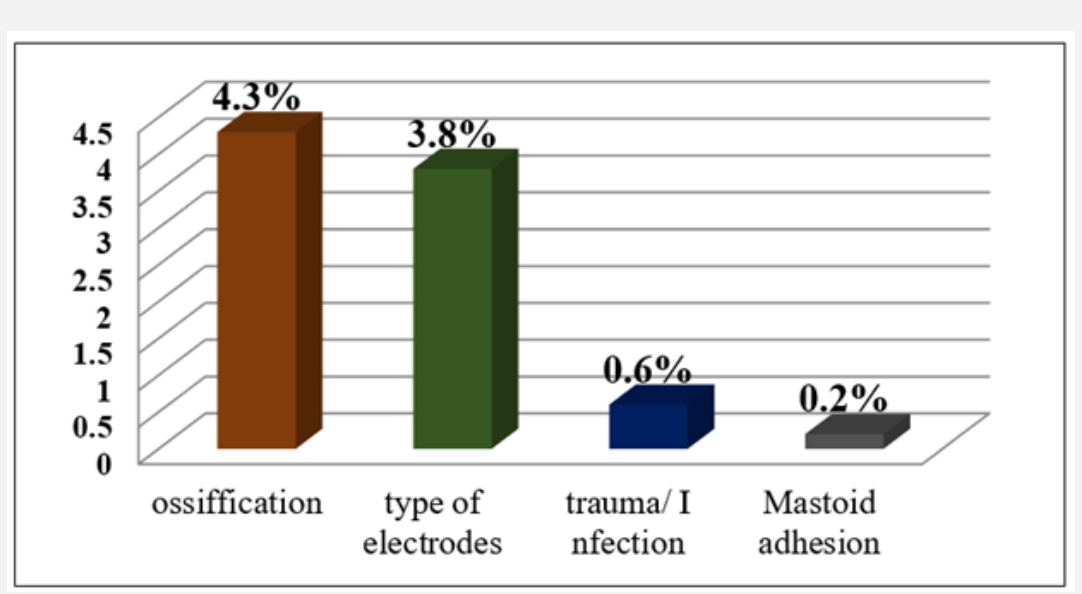

Figure 4: Frequency of factors causing electrode migration post cochlear implant.

\section{Discussion}

Electrode migration is an underrated complication of post cochlear implant; therefore, it is the least discussed topic remained in research. A review study by Green et al described that $6.25 \%$ complications reported in post cochlear implant out of which $1.25 \%$ were of electrode migration in first 6 months of duration [18]. A study conducted by Ronald et al showed that in 5 years of duration patients follow up post cochlear implant and there is no electrode migration reported as in cochlear implant they have used titman clip and split bridge and it is known for stable fixation in cochlear implant [19]. In current review it has been cleared that electrode migration is cause of device failure although use stable fixation because it is least effective in fully ossified cochlea [20].

As electrode related device failure like migration, misplacement and excursion is not a well-known complication, because sound awareness must detect electrode migration in post CI patients. A First study by Waltzman et al. [21] that proved electrode migration without pain and symptoms can be occurred [21]. There are advance bionics computerized tomography (CT scan) considered as important in the measurement of electrode migration. In this study it has been observed that migration is irrelevant to insertion depth, and it is shown that only two patients developed a drop in speech perception to those patients who had electrode migration more than $>1 \mathrm{~mm}[8,18]$ and Fixation clip techniques can minimize electrode migration issue.

In a study conducted by Mittman et al has described those fixation techniques like fixation clips can be thought to minimize the risk of electrode migration or misplacement [7]. In one study by Kubo et al described that electrode extrusion is although rare complication but it can lead to re implantation surgery and it may occur after a few years from surgery but fixation of the electrode 
into split made in the buttress part may prevent electrode migration [22]. If external bony canal has become thinner during facial recess approach it would be repaired with bone or cartilage plate $[11,12]$. Current study gives detailed review about importance of electrode migration as this is a neglected complication in post cochlear implant patients. Advance research design and more precise scientific study is needed to know more details about possible causative factors for electrode migration.

\section{Conclusion}

Electrode migration is not well defined in the literature. Moreover, different fixation techniques are more reliable to avoid migration and extrusion of electrode which could cause device failure. However, there is a need for special attention, particularly on the fixation of straight electrode arrays. Reducing the force of migration in the form of advance fixation technique can reduce the incidence of electrode migration.

\section{References}

1. Kim LS, Jeong SW, Lee YM, Kim JS (2010) Cochlear implantation in children. Auris Nasus Larynx 37(1): 6-17.

2. Jackler RK, Luxfor WM, House WF (1987) Congenital malformations of the inner ear: a classification based on embryogenesis. Laryngoscope 97(S40): 2-14.]

3. Kaga K (2017) Embryology of Inner Ear and Its Malformation. In Cochlear Implantation in Children with Inner Ear Malformation and Cochlear Nerve Deficiency, Springer, Singapore, Pp 11-18.

4. Amarnath C, Sathyan G, Soniya R, Periakaruppan AL, Shankar KS (2016) Evaluation of embryological sequences of ear anomalies and its radiological relevance. Indian J Otol 22(4): 248.

5. Dhanasingh A, Jolly C (2017) An overview of cochlear implant electrode array designs. Hearing research 356: 93-103.

6. Masterson L, Kumar S, Kong J H K, Briggs J, Donnelly N, et al. (2012) Cochlear implant failures: lessons learned from a UK centre. J Laryngol Otol 126(1): 15-21.

7. Mittmann P, Rademacher G, Mutze S, Ernst A, Todt I (2015) Electrode migration in patients with perimodiolar cochlear implant electrodes. Audiol Neurootol 20(6): 349-353.

8. Leinung M, Helbig S, Adel Y, Stöver T, Loth A G (2019) The effect of a bone groove against cochlear implant electrode migration. Otol Neurotol 40(5): e511-e517.
9. Ikeya J, Kawano A, Nishiyama N, Kawaguchi S, Hagiwara A, et al. (2013) Long-term complications after cochlear implantation. Auris Nasus Larynx 40(6): 525-529.

10. Connell SS, Balkany TJ, Hodges AV, Telischi FF, Angeli SI, et al. (2008) Electrode migration after cochlear implantation. Otol \& Neurotol 29(2): 156-159.

11. Holder JT, Kessler DM, Noble JH, Gifford RH, Labadie RF (2018) Prevalence of extracochlear electrodes: computerized tomography scans, cochlear implant maps, and operative reports. Otol Neurotol 39(5): e325-331.

12. Sunde J, Webb JB, Moore PC, Gluth MB, Dornhoffer JL (2013) Cochlear implant failure, revision, and reimplantation. Otol Neurotol 34(9): 1670-1674.

13. Brown KD, Connell SS, Balkany TJ, Eshraghi AE, Telischi FF, et al. (2009) Incidence and indications for revision cochlear implant surgery in adults and children. Laryngoscope 119(1): 152-157.

14. Van Der Marel KS, Verbist BM, Briaire J J, Joemai RM, Frijns JH (2012) Electrode migration in cochlear implant patients: not an exception. Audiol Neurotol 17(5): 275-281.

15. Dietz A, Wennström M, Lehtimäki A, Löppönen H, Valtonen H (2016) Electrode migration after cochlear implant surgery: more common than expected? Eur Arch Otorhinolaryngology 273(6): 1411-1418.

16. Vaid N, Roland JT, Vaid S (2011) Extracochlear electrode extrusion. Cochlear Implants Int 12(3): 177-180.

17. Di Laora A, Mosnier I, Ciorba A, Pelucchi S, Sterkers O, et al. (2019) Cochlear Implant Electrode Migration due to Cholesterol Granuloma: Cues from a Case. J Int Adv Otol 15(3): 467-469.

18. Green KM, Bhatt YM, Saeed SR, Ramsden RT (2004) Complications following adult cochlear implantation: experience in Manchester. J Laryngol Otol 118(6): 417-420.

19. Roland JT, Fishman AJ, Waltzman SB, Alexiades G, Hoffman RA, et al. (1998) Stability of the cochlear implant array in children. Laryngoscope 108(8): 1119-1123?

20. Chua SJ, Ke L, Kumar RS, Zhang K (2002) Stabilization of electrode migration in polymer electroluminescent devices. Appl phys lett 81(6): 1119-1121.

21. Waltzman SB, Cohen NL, Green J, Roland JT (2002) Long-term effects of cochlear implants in children. Otolaryngol Head Neck Surg 126(5): 505-511.

22. Kubo T, Matsuura S, Iwaki T (2005) Complications of cochlear implant surgery. Operative Techniques in Otolaryngology-Head and Neck Surgery 16(2): 154-158.

\section{Your next submission with Juniper Publishers will reach you the below assets}

- Quality Editorial service

- Swift Peer Review

- Reprints availability

- E-prints Service

- Manuscript Podcast for convenient understanding

- Global attainment for your research

- Manuscript accessibility in different formats

( Pdf, E-pub, Full Text, Audio)

- Unceasing customer service

Track the below URL for one-step submission https://juniperpublishers.com/online-submission.php 